\title{
PANORAMA CRÍTICO DE LOS HITOS DEL DRAMA CHILENO EN LA REVISTA CHILENA DE LITERATURA
}

\author{
Carolina Brncić \\ Universidad de Chile \\ Santiago de Chile, Chile \\ cbrncic@gmail.com \\ Eduardo Thomas \\ Universidad de Chile \\ Santiago de Chile, Chile \\ oscthomas@gmail.com
}

RESUMEN / ABSTRACT

Este artículo ofrece un panorama histórico y crítico de la evolución del drama chileno a lo largo de los siglos XX y XXI, horizonte elaborado a partir de la revisión de los estudios publicados en la Revista Chilena de Literatura desde su fundación en 1970 hasta el año 2018. Se detiene en dramaturgos y dramaturgas, así como en obras destacadas por los distintos trabajos, acogiendo una diversidad de perspectivas teóricas y críticas, y relacionándolas transversalmente. Un resultado relevante de este recorrido consiste en la construcción de un canon y una tradición ordenadores de nuestra dramaturgia nacional; otro, no menos importante, es la puesta en relieve de la contribución de la Revista Chilena de Literatura a la reflexión crítica y teórica sobre la dramaturgia chilena.

PALABRAS ClAVE: drama chileno, teatro, tradición nacional, canon, intertextualidad.

\section{CRITICAL PANORAMA OF THE CHILEN DRAMA MILESTONES IN THE REVISTA CHILENA DE LITERATURA}

This article provides an historical and critical panorama about Chilean drama throughout the XX and XXI centuries, based on the review of papers published in the Revista Chilena de Literatura since 1970 until 2018. This study examines some prominent playwriters and plays emphasized in different papers, embracing dissimilar theoretical and critical approaches, which are related to each other. Our purpose is two-fold; first, build a canon and a tradition which will order our national dramaturgy; second, but no less important, demonstrate the 
contribution of the Revista Chilena de Literatura on the critical and theoretical studies of Chilean dramaturgy.

KEYWORDS: Chilean drama, theatre, national tradition, canon, intertextuality

Recepción: 04/04/2019

Aprobación: 26/07/2019

El propósito de este trabajo es examinar un área específica dentro del conjunto de artículos publicados en la Revista Chilena de Literatura desde su creación hasta la actualidad: la dedicada a la dramaturgia chilena. Si bien el volumen de estudios es menor al destinado a otros géneros literarios, las contribuciones críticas han sido permanentes a lo largo de los años, desde su número inaugural.

Nuestro objetivo principal es ofrecer un panorama transhistórico de los principales hitos en el drama chileno del siglo XX, tomando en consideración dos aspectos: el primero, referir a aquellos autores y autoras que han conformado un canon en la tradición dramática nacional a partir de sus obras y sus propuestas autoriales individuales; y el segundo, describir cómo esta tradición se perfila en tendencias claramente reconocibles a partir de la continuidad de temas, estrategias y procedimientos, al tiempo que se renueva en los aportes y propuestas que va sumando cada dramaturgo.

Para reconstruir este panorama dramático nacional tomaremos como sustrato crítico en primer lugar trabajos publicados en la Revista Chilena de Literatura, particularmente aquellas colaboraciones que en sus estudios de obras y/o autores dan cuenta del asentamiento o renovación de este canon ${ }^{1}$ -en algunos casos puntuales incluiremos también otras referencias críticas para ampliar la reflexión-. A partir de este acervo crítico que nos precede, consideramos que en el conjunto de los diferentes artículos que citaremos de la Revista es posible comprobar que existe una tradición en el drama chileno fundada en el diálogo ejercido por los dramaturgos a través del tiempo. Esta comprobación permite, a su vez, constatar la solidez artística, literaria y cultural, de una dramaturgia consciente de sí misma, de su propia historia y en relación directa con los procesos históricos nacionales.

\footnotetext{
Las características y extensión de este trabajo impiden la referencia a todos los artículos sobre teatro chileno publicados en la Revista Chilena de Literatura. Para un conocimiento completo de este corpus remitimos al Apéndice final que incluye todas las colaboraciones.
} 
En nuestra opinión, el desarrollo dramático está indisociablemente ligado al devenir y transformaciones históricas y sociales del país. Es por ello que un primer fundamento para nuestra aproximación será el concepto de época literaria propuesto por Cedomil Goic en Los mitos degradados (1992), quien la define como un módulo histórico extenso, multisecular, cuyos límites se definen por la vigencia de un sistema dominante conformado por tres categorías fundamentales: el concepto y función de la literatura; la representación de la realidad y la construcción de los géneros literarios. Según esta idea, durante una época literaria predomina una concepción de la literatura (correspondiente a una peculiar concepción del mundo manifiesta en todas las áreas de la cultura durante ese lapso histórico), que se traduce en un modo definido de representar la realidad humana y también en una manera peculiar de elaborar los textos literarios. Cada época evoluciona como un proceso en el que las obras constituyen exploraciones de las posibilidades que han abierto las matrices textuales y de sentido establecidas por los escritores que asumieron inicialmente la nueva concepción cultural y literaria (291-299).

Es a partir de esta concepción que estableceremos cuatro épocas literario-dramáticas para nuestra revisión crítica. Estos cuatro momentos se corresponden con: un momento inicial denominado "Los dramaturgos de las primeras décadas del siglo XX" que congrega las figuras de Germán Luco Cruchaga, Armando Moock, Antonio Acevedo Hernández y Vicente Huidobro, considerados los fundadores de un nuevo paradigma dramático que busca distanciarse del realismo decimonónico, configurando al mismo tiempo las características de una dramaturgia 'nacional' con características singulares. Un segundo momento, dedicado al quehacer dramático de las décadas de 1950-1960, revisitado a partir de las poéticas de Egon Wolff y Jorge Díaz. Sus dramaturgias, influidas por la vanguardia europea, amplían temática y estéticamente la 'tradición chilena' a partir de la innovación en sus matrices textuales. Un tercer momento que ubicamos en las décadas de 1980 y 1990 con las expresiones dramáticas en dictadura y durante la transición política, descrito a partir de dos figuras paradigmáticas, Juan Radrigán y Marco Antonio de la Parra que, haciéndose cargo de la denuncia y/o diagnóstico de la sociedad de la época, elaboran propuestas y tendencias diametralmente opuestas que pueden leerse como bisagras frente a la tradición anterior y los creadores posteriores. Finalmente, la revisión del cuarto momento, "Las dramaturgias del nuevo milenio", se detiene en la propuesta estética de Manuela Infante y su trabajo con 'materiales' históricos, literarios y dramáticos para describir sucinta y panorámicamente la diversidad de propuestas dramatúrgicas desde el año 2000 hasta la actualidad. 
En nuestro recorrido hemos procurado establecer algunas líneas argumentales que permiten relacionar los distintos momentos y propuestas dramáticas entre sí, para demostrar la continuidad e innovación en la tradición dramática teatral. Una de ellas se resume en la idea consustancial al teatro de representación de la realidad. En los distintos momentos observaremos cómo los creadores buscan formas y modos alternativos para recrear la realidad, intentando distanciarse del realismo decimonónico como paradigma mimético sin renunciar a la incorporación y representatividad de lo real. Esto último permite delinear al menos dos tendencias que no se excluyen entre sí, que se originan ya con Acevedo y Huidobro y que persisten, con transformaciones, en las épocas posteriores: nos referimos a una tendencia que incorpora una representatividad, social, popular, local y nacional; y otra que experimenta con las formas dramáticas, en la línea de las búsquedas vanguardistas (simbolistas, creacionistas, surrealistas, expresionistas, absurdistas). Otra línea argumental se centra en el trabajo textual de los creadores, explicitando la importancia que cobra la 'intertextualidad' en el quehacer dramático. Este dialogismo con otros textos de la literatura nacional, latinoamericana y universal y con el relato histórico chileno es una constante en los cuatro momentos reseñados. Nos parece importante esta dimensión, por cuanto refuerza la idea de construcción de un canon que poco a poco se amplía, configurando una tradición que se inicia en los albores del siglo pasado y se proyecta sólidamente hasta el presente.

\section{LOS DRAMATURGOS DE LAS PRIMERAS DÉCADAS DEL SIGLO $\mathrm{XX}$}

Durante las primeras décadas del siglo XX se desarrolló en la cultura chilena un cambio de paradigma cultural que en la literatura se tradujo en transformaciones profundas y esenciales en los géneros literarios -entre ellos, aunque su asunción del nuevo sistema estético es más lenta y dificultosa, el drama-, que mantiene su desarrollo hasta nuestros días. En la esfera literaria el cambio de época se inició con un distanciamiento más o menos radical del realismo dominante en el paradigma decimonónico anterior, en aspectos que atañían a la construcción de los relatos y personajes, a la elaboración de los mundos ficcionales y a la concepción que manifestaban los textos de la función social de la escritura literaria. La evolución de la nueva época se da desde el realismo de fundamentos positivistas y programáticos heredado del 
siglo XIX, hacia el irrealismo modernista y vanguardista; hacia la autonomía de la literatura y la libertad creadora que ella posibilita; hacia la construcción textual como "obra abierta", "inorgánica", que exige una nueva y activa función al lector/espectador como partícipe y responsable en el proceso de creación.

En las décadas de 1920 y 1930 destacan nítidamente cuatro dramaturgos chilenos por el volumen, calidad literaria y novedad artística de su producción. Han sido reconocidos por la crítica como referentes ineludibles en el panorama histórico del drama chileno. Estos dramaturgos son Germán Luco Cruchaga, Armando Moock, Antonio Acevedo Hernández y Vicente Huidobro.

Germán Luco Cruchaga es el creador de La viuda de Apablaza (1928), obra que se considera la culminación del naturalismo en el drama chileno y una expresión poderosa y sólida del género trágico en nuestra dramaturgia. La elaboración del mito de Fedra como fundamento de la trama y los elementos freudianos de su reformulación en el conflicto de la protagonista con su hijastro hacen trascender a esta obra el realismo naturalista proveniente del siglo anterior por la profunda complejidad de los personajes que supera ampliamente la estética positivista. La crítica ha interpretado su argumento como una alegoría de las transformaciones del orden social campesino en el marco de los programas sociales de la época.

Armando Moock, dramaturgo de una extensa y exitosa producción, es el autor de Pueblecito (1918), drama que ha sido reconocido como un texto fundacional del teatro chileno. La crítica alaba su excelente construcción dramática, y también destaca su actualización del tema de la oposición entre campo y ciudad, heredado del Romanticismo. En el primer número de la Revista Chilena de Literatura, el trabajo de Antonio Skármeta: "El motivo de la oposición entre aldea y ciudad en dos dramas chilenos" (1970), compara la actualización de este motivo en Pueblecito y en La canción rota (1921) de Acevedo Hernández. Lo novedoso de la dramaturgia de Armando Moock reside en la elaboración de los conflictos de los protagonistas como procesos interiores que los llevan ineluctablemente a rescatar su libertad ejerciendo con lucidez la elección de sus opciones de vida. Esta interiorización existencial de la acción en las obras de Moock va acompañada, necesariamente, de innovaciones en todos los niveles de sus textos dramáticos, las que son difíciles de percibir tras la estética melodramática y aparentemente costumbrista de sus piezas. Se ha observado, sin embargo, que los tipos pueblerinos que presenta Pueblecito no van acompañados del detallismo en los elementos regionales propio del costumbrismo, lo que favorece la universalidad del mundo presentado. A esta observación, aplicable a toda la producción de Moock, puede agregarse la 
ruptura, a veces violenta, de los códigos culturales de su tiempo, apreciable en sus mejores dramas, en especial en la representación de la mujer.

Pensamos que los realismos de Moock y Luco Cruchaga constituyen antecedentes de una larga y constante dramaturgia realista social, centrada en la rebeldía de los y las protagonistas ante los códigos y convenciones sociales, presente en el teatro chileno durante todo el siglo XX y hasta nuestros días.

Los otros autores en las décadas de 1920 y 1930 que aportan matrices textuales innovadoras en el drama chileno son Antonio Acevedo Hernández y Vicente Huidobro, ambos iniciadores de dos modos diferentes de vanguardia en la dramaturgia chilena: el primero con su teatro poético y social; el segundo con su dramaturgia creacionista.

Antonio Acevedo Hernández tuvo como proyecto central de su escritura dramática incorporar la cultura popular, con su arte, sus voces, sus conflictos y su cosmovisión, como elemento esencial, a la expresión literaria de nuestro país. Esta era la misión que se propuso como escritor: la creación de un mundo ficcional literario y artístico que no solo denunciara las injusticias que sufrían las clases campesina y obrera, y sirviera para impulsar la causa de sus reivindicaciones; también era su propósito que ese mundo ficcional expresara en toda su riqueza los valores de la cultura popular tradicional. En el concepto de Acevedo, un teatro limitado a la realidad y percepción de la oligarquía dominante, como ocurría con el teatro chileno hasta entonces, era irremediablemente ajeno a la realidad profunda del país y en consecuencia un teatro incapaz de representarla. Para crear una dramaturgia que interpretara a la sociedad chilena real, el autor llevó a la escena al mundo popular con su oralidad, folclore, memoria, leyendas y mitos; su arte y sus fiestas, además de sus sufrimientos, luchas y demandas de justicia.

Su programa contemplaba representar lo popular asumiendo las formas y recursos del teatro europeo moderno: sus obras, especialmente las de su madurez como creador, no solo renovaron la dramaturgia nacional con su temática social, función activista y oralidad popular; también modernizó y actualizó los modos de construcción dramática y representación teatral. Esto último es notorio en la interiorización y subjetivización de los espacios y la acción en sus piezas, así como en los fundamentos mítico-simbólicos de los mismos; en la modalidad expresionista que asume la representación en algunas de sus obras; en la utilización de técnicas como la fragmentación del espacio escénico, las transparencias o las proyecciones cinematográficas para representar procesos de conciencia de los personajes como evocaciones familiares o alucinaciones, elementos todos que otorgan agilidad al relato 
dramático y complejidad a la elaboración del tiempo ficcional. No debemos olvidar el especial "anarquismo cristiano" que inspira la producción literaria de Acevedo Hernández y le da solidez ética e ideológica. Los imaginarios provenientes de la tradición adquieren en sus obras significación novedosa y universal al reinterpretarse desde esa perspectiva.

Estas características de la dramaturgia de Acevedo -reconocibles en plenitud en sus obras más conocidas como La canción rota (1921) y Chañarcillo (1936)- demuestran su conocimiento y apropiación de tendencias del teatro moderno europeo: el drama expresionista, la dramaturgia de vanguardia social y política de Piscator, el teatro poético, entre otras. La elaboración del mundo y el arte populares chilenos con las formas y recursos del teatro moderno occidental da a la producción de este autor una gran originalidad y potencia renovadoras que justifican su reconocimiento como piedra fundacional del teatro moderno chileno.

Los escasos estudios publicados en la Revista dedicados a este dramaturgo profundizan estas cualidades de su producción.

En su trabajo ya mencionado sobre "El motivo de la oposición entre aldea y ciudad en dos dramas chilenos" (1970), Skármeta observa la función del correlato con el Evangelio en La canción rota como un recurso para incorporar una dimensión alegórica a la historia representada. Si la oposición entre aldea y ciudad en las obras de Moock y Acevedo cobra un nuevo sentido por la acción de un nuevo sujeto moderno y rebelde capaz de imponerse al medio social, la revolución que genera el personaje de Salvador en La canción rota cobra profundidad y universalidad poéticas mediante el referente intertextual de la historia de Cristo. La violencia campesina con que se cierra la obra se legitima por la reinterpretación anarquista de la buena nueva cristiana difundida por la enseñanza de Salvador a los campesinos.

Los estudios de Sergio Pereira y Mauricio Barría profundizan la lectura de la dramaturgia de Acevedo Hernández en su dimensión simbólica y transgresora de las normas del realismo vigentes en el teatro chileno de su tiempo. El artículo de Pereira "El drama legendario y bíblico de Antonio Acevedo Hernández" (1999), estudia el efecto innovador que tiene en la dramaturgia de este autor la elaboración dramática de leyendas chilenas e historias bíblicas. Las leyendas le permitieron incorporar a su mundo dramático lo maravilloso, recurso que le permitió trascender el realismo tradicional e incorporar nuevas técnicas en la construcción del tiempo y del espacio ficcionales; es significativo el sentido de recuperación de los valores primordiales de la cultura ancestral que Acevedo otorgó a la recuperación 
artística de las leyendas chilenas. Los dramas de asunto bíblico, por su parte, mantienen el pasado absoluto de los relatos en el texto original; pero los modifican para darles el valor de alegorías que refieren críticamente a las contradicciones e injusticias del mundo moderno.

En el estudio "Interrupciones momentáneas de la convención. Aportes para la comprensión de Irredentos de Antonio Acevedo Hernández" (2015), Mauricio Barría Jara destaca la conciencia artística de este dramaturgo, evidente en su disconformidad con la situación de inconsciente retraso que percibía en el teatro chileno de su tiempo, que se mostraba ajeno a la acción renovadora de las vanguardias artísticas y a la amenaza del cine. El artículo interpreta el sentido que adquieren en algunos dramas de Acevedo ciertas marcas textuales constitutivas de rupturas respecto de las formas y discursos dominantes en el teatro chileno de esos años, a las que denomina “interrupciones momentáneas de la convención”, apoyándose en las ideas de "convencionalidad" de Raymond Williams y de "técnica" de Walter Benjamin. En su estudio de la obra Irredentos (1918), identifica como desviación de la convención su elaboración crítica del tema de la huelga. En efecto, Acevedo representa sin atenuantes las consecuencias catastróficas para los trabajadores que trae el recurso de una huelga asumida de modo irreflexivo por sus dirigentes. También señala como una desviación de la convención la representación escénica, en el tercer acto, de una asamblea de trabajadores discutiendo y votando una huelga indefinida. Tanto el punto de vista crítico sobre el recurso de la huelga irreflexiva, como la escenificación de una asamblea obrera ejerciendo su voto, constituyen ejemplos en la obra de Acevedo Hernández de su desvío desafiante y renovador respecto de las convenciones teatrales de su tiempo.

Los artículos mencionados coinciden en atribuir a la dramaturgia de Antonio Acevedo Hernández un lugar destacado entre los fundadores del drama chileno moderno, por sus innovaciones tanto en la representación ficcional como en la construcción del drama; pero también y, sobre todo, por la configuración en sus obras de una nueva modalidad de sujeto, perceptible tanto en sus personajes protagónicos (rebeldes, conscientes, libertarios) como en la del dramaturgo presente en sus textos (informado, consciente y crítico de sus contextos artísticos).

En verdad, creemos que su obra tiene continuidad en por lo menos dos líneas posteriores de producción en la dramaturgia chilena. Una de ellas corresponde a lo que Elena Castedo-Ellerman (1982) ha denominado 'folclorismo', tendencia de importante desarrollo en la década de 1960 en la 
que pueden incluirse numerosas piezas de dramaturgos como Luis Alberto Heiremans, Jaime Silva e Isidora Aguirre, por nombrar los más relevantes. La otra es la del teatro de denuncia y activismo social, a la que de diferentes formas también adscriben los dramaturgos mencionados (puesto que la elaboración poética del folclore y el brechtianismo, compartidos en diversos grados y maneras por los tres, en sus obras son inseparables de la denuncia social), y en la que destaca de manera especial Juan Radrigán.

El otro autor dramático de principios del siglo XX del que se desprende una línea de producción muy nítida en la historia del teatro chileno es Vicente Huidobro. Conocido universalmente como poeta, escribió también narrativa y dos obras dramáticas (a las que podría sumarse un guión para cine).

Sus dos obras para teatro, Gilles de Raiz y En la luna, asumen su poética creacionista con el explícito objetivo de renovar la dramaturgia chilena. Lo hacen apropiándose de las formas de la vanguardia europea. Gilles de Raiz está construida con elementos provenientes tanto del surrealismo, como del ritualismo y ceremonia propios de ciertas modalidades del teatro de vanguardia, elaborando la figura histórica y legendaria del lugarteniente de Juana de Arco sobre la base del mito de Barba Azul, haciendo de ella una metáfora del

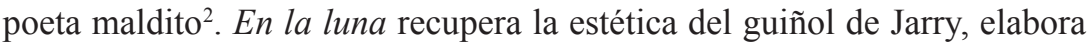
una dramaturgia de vanguardia centrada en la desconstrucción de las formas discursivas y literarias dominantes, mediante la parodia, la ironía y el humor. $\mathrm{Su}$ fuerte contenido crítico a la realidad política chilena y latinoamericana justifica plenamente que la académica Lidia Neghme definiera su concepción estética como "creacionismo político".

Sergio Saldes Báez dedica su artículo "El juego de los espejos. Función ideológica y función poética en En la luna de Huidobro" (1987), a estudiar esta segunda pieza dramática del poeta desde el punto de vista de la conciliación que en ella se da entre la poética creacionista del autor y su función de activismo político e ideológico. La organización del texto en varios niveles ficcionales que juegan especularmente entre ellos muestra la construcción del texto y provocan el distanciamiento del lector/espectador, consagrando así la autonomía estética de la obra, y también favoreciendo su recepción crítica. Por otra parte, el humor es un recurso que opera mediante la elaboración paródica del lenguaje. El trabajo de Saldes enfatiza el carácter intensamente 
poético de En la luna, comprobable en los variados modos con que esta pieza teatral se refiere permanentemente a su propia creación. También demuestra que su estética creacionista no impide que se refiera críticamente a la realidad histórica chilena y latinoamericana, transmitiendo un mensaje de rebeldía social y utopismo político.

Ambas obras son antecedentes de formas vanguardistas que emergen en el teatro chileno durante la década de 1960 . No es difícil vincular el muy personal teatro del absurdo elaborado por Jorge Díaz, especialmente en su producción inicial, con la construcción textual y los juegos lingüísticos de En la luna. Por otra parte, el fuerte contenido ritual de sus piezas y su constante tematización del sexo, la crueldad y la imaginación poética como facultad liberadora son reconocibles muy definidamente en Gilles de Raiz. El propio Jorge Díaz reconoció la importancia del creacionismo huidobriano para su concepción artística ${ }^{3}$.

Como veremos más adelante, a través de Jorge Díaz esta modalidad de dramaturgia vanguardista es recogida más tarde por Marco Antonio de la Parra y por Benjamín Galemiri: ambos dramaturgos cultivan un "creacionismo político" basado en juegos de lenguaje que recuerdan en muchos aspectos la estética absurdista de En la luna. También veremos que en la obra inicial de Manuela Infante existen rasgos que permiten relacionarla con la estética huidobriana. Esta joven dramaturga comparte con el poeta la construcción irrealista de personajes históricos con sentido político; el juego con la intertextualidad paródica y la construcción lúdica de los diálogos. En su obra Juana existen alusiones sutiles a Gilles de Raiz que constituyen una forma de reconocimiento de Infante a Huidobro.

\section{DOS DRAMATURGOS DE MEDIADOS DEL SIGLO XX}

El movimiento de los teatros universitarios iniciado el año 1941 con la fundación del Teatro Experimental de la Universidad de Chile llevó a cabo un programa modernizador de la actividad teatral en el país, considerándola de modo integral: desde la actualización del repertorio de obras teatrales y la

3 Una vinculación consciente con la poética de Vicente Huidobro se manifiesta en el epígrafe de El velero en la botella (1962) y en el monólogo de su protagonista David cuando descubre el poder creador del lenguaje. 
profesionalización de los artistas en escuelas especializadas hasta la creación de un público y la producción de una dramaturgia nacional. Producto de la realización de este programa fue la consolidación de una actividad teatral sistemática, profesional y altamente consciente de las exigencias del nuevo ambiente artístico generado por las escuelas de teatro universitarias. A partir de estas instituciones y del vigoroso medio teatral generado por el proyecto desarrollado por ellas, en la década de 1960 inicia su producción un brillante grupo de dramaturgos chilenos cuya producción artística se desarrolla con su apoyo y estímulo. Es destacable en estos dramaturgos su conciencia de pertenecer a un medio artístico en el que se comparten experiencias y criterios; $y$ en el que escritores y artistas se conocen y dialogan. Estos dramaturgos constituyen la expresión teatral del movimiento denominado "Generación del 50" en las esferas de la literatura y las artes. Figuras ampliamente destacadas en esta generación de dramaturgos son Jorge Díaz y Egon Wolff, no solamente por el volumen y la calidad de su producción dramática -reconocida internacionalmente-; también por su capacidad de renovar su escritura constantemente, acogiendo con notable sensibilidad los problemas, temas y tendencias que aparecían en el curso de la historia.

En el trabajo "Representación y trascendencia de lo absurdo en el teatro chileno contemporáneo" (1999), Eduardo Thomas identifica como una constante en la dramaturgia de Jorge Díaz una mítica del lenguaje poético que ve en la imaginación creadora una posibilidad de trascender la experiencia absurda del mundo. Desde las primeras piezas de este autor es fundamental el tema de la capacidad cognoscitiva y liberadora de la palabra poética, tema que, con variaciones, atraviesa toda su producción. En su dramaturgia inicial, que el artículo ejemplifica con El cepillo de dientes (1961), el lenguaje de los medios de comunicación aparece parodiado y denunciado por sus efectos alienantes sobre los protagonistas, que se refugian y enmascaran en sus enunciados vacíos para no enfrentar la realidad. La posibilidad de relacionarse de una manera auténtica con el lenguaje y tratar de enunciar la "palabra justa" y liberadora está siempre abierta para ellos, como proponen al final del segundo acto, pero optan en definitiva por continuar en el "parque de diversiones" de los medios de comunicación. En la producción madura del dramaturgo, la palabra poética sigue constituyendo un tema fundamental. El cambio se encuentra en la valoración del sentimiento como único elemento capaz de otorgar sentido y valor de verdad a los actos de habla. Es lo que ocurre a la pareja de ancianos protagonistas de El locutorio (1976), que inventan un pasado común en sus periódicos diálogos en el locutorio de una institución 
cuya índole no se aclara en el texto. Los personajes están separados por rejas y el escenario está también cerrado por una reja que separa al público del espacio de los actores. Los dos personajes ignoran la identidad del otro y declaran ser el visitante y el otro el asilado. Solo se conocen mediante la ficción que han creado entre los dos. En estas circunstancias, la única verdad que les resta es la historia inventada, que finalmente se legitima por el amor de los personajes.

Otro artículo dedicado a Jorge Díaz es de Fernando Burgos: "Estética de la ironía en el teatro de Jorge Díaz" (1986). Se refiere a las funciones de esta figura en tres obras del dramaturgo, especialmente a su sentido cuestionador de la capacidad comunicativa del lenguaje en una cultura dominada por la tecnología de los medios de comunicación. En la pieza breve El génesis fue mañana (1965), la paradoja del título corresponde a la representación en la obra de un Génesis imposible en el contexto del Apocalipsis de un mundo reducido a chatarra. En ese espacio los actos de habla están condenados al fracaso antes de ser emitidos. En El cepillo de dientes, el cuestionamiento de las posibilidades de comunicación de la pareja protagónica da lugar al despliegue de un juego comunicativo de carácter lúdico por parte de ambos, que aparte de mostrarse como la "transformación de una carencia", también puede interpretarse como un recurso irónico por parte de los personajes para "buscar en el juego y el humor, la representación y la teatralidad, los modos y efectos de una liberación" (139). El mismo sentido de la ironía realizada como paradoja se encuentra en Topografía de un desnudo (1967). El subtítulo, "Esquema para una indagación inútil", sugiere que la obra está destinada al fracaso, porque su denuncia será anulada por los poderes institucionales. La única estrategia posible para evitar el fracaso comunicacional es la que adopta la obra: criticar directamente en sus raíces al lenguaje institucional: el periodístico, el estadístico, el técnico. Este procedimiento alcanza en sus cuestionamientos a los recursos del teatro moderno: la obra innova en sus modos de construcción y representación, incorporando recursos tecnológicos y lenguajes capaces de apelar al espectador/lector y abrirle perspectivas sobre el horror de los acontecimientos denunciados. De esta manera, la ironía refiere también a la imposibilidad de realizar teatro sin renovar sus medios de expresión para trascender las convenciones del lenguaje vigente. La crítica a las convenciones del lenguaje es fundamental en la poética de Jorge Díaz.

Como mencionamos anteriormente, el otro dramaturgo de la promoción al que la Revista ha dedicado estudios es Egon Wolff. Si se busca una constante en la dramaturgia de este autor, pensamos que la más evidente 
es su representación crítica de la burguesía. En sus dramas, el burgués aparece con una apariencia exterior segura y poderosa, que enmascara su interioridad profundamente precaria, insatisfecha e insegura, asediada por el sentimiento más o menos inconsciente de sustentar un orden excluyente y cerrado, próximo a su fin ${ }^{4}$.

Esta imagen de la burguesía se encuentra ya en sus primeras obras de carácter realista. Más tarde, en las obras que lo hacen conocido internacionalmente, recibe una elaboración expresionista con valor alegórico: nos referimos a Los invasores (1963), Flores de papel (1970), La balsa de la Medusa (1984). En el realismo de su producción posterior, el asunto sigue presente, y es elaborado en su obra Cicatrices (1994) con rica y compleja profundidad literaria.

En el artículo "El juego y el rito como fundamento de la estructura dramática en tres obras de Egon Wolff: Los invasores, Flores de papel y Cicatrices (2005), Eduardo Thomas estudia la función de lo ritual y lúdico en la interpretación que el dramaturgo da a este tema en las tres obras mencionadas. Observa cómo la historia representada en la primera de estas obras es un sueño del industrial Lucas Meyer, pesadilla que adopta las formas de un delirante rito iniciático en el que el burgués debe enfrentarse a sus propios temores y culpas, simbolizadas por los marginales que invaden su casa. La invasión adopta las formas de un constante y variado juego cuyo sentido no es capaz de comprender la lógica empresarial del industrial. Tal como ocurre a Eva, protagonista de Flores de papel, ante la presencia del vagabundo Merluza que invade su departamento, Lucas Meyer no entiende que el objetivo del juego de los marginales que lo invaden no es el poder, sino obligarlo a enfrentarse a sus propias contradicciones. Tampoco es capaz de percibir este enfrentamiento como una oportunidad para reconstruirse como sujeto e iniciar una nueva existencia más plena, libre de compromisos y culpas. En la lectura que propone este artículo, el concepto del juego como actividad creadora de ficción, gratuita y libremente asumida por cada jugador, es fundamental. También la imagen junguiana de la "sombra" como mensajero

\footnotetext{
$4 \quad$ Para profundizar en la representación de la burguesía, véase los artículos de Iván Carrasco "Flores de papel de Egon Wolff: la crisis de la identidad" (1982) y de Antonio Skármeta: "La burguesía invadida: I. Egon Wolff” (1971).
} 
del inconsciente que presenta a los protagonistas sus carencias simbolizadas por los juegos de los marginales 5 .

En la obra Cicatrices, los personajes realizan un juego basado en la trama de la novela Las afinidades electivas de J.W. Goethe, estimulados por la semejanza de las circunstancias que están viviendo en la casa de campo de Ernesto y Olivia, quienes han encargado remodelarla a su amigo, el arquitecto Germán. El artículo analiza el correlato de la obra teatral con la novela, comprobando que en ambas el juego adopta las características de un rito conducente al sacrificio de una joven sobrina de la dueña de casa, de condición económica más pobre, a la que reciben para darle alojamiento, apoyo y protección. Si en la novela de Goethe el juego comprueba trágicamente la teoría de las "afinidades electivas" y, con ella, el determinismo que operan las leyes naturales sobre los sentimientos y relaciones humanas, en la obra de Wolff el juego iniciado por los personajes solo pretende comprobar la efectividad de la teoría expuesta por la novela de Goethe para aliviar la alienación en que transcurren sus existencias. La trama se desarrolla como un perverso rito conducente al sacrificio de la niña Beatriz, cuya muerte gravitará sobre los adultos como una culpa sin redención posible, pero que al mismo tiempo aliviará el vacío de las existencias de los personajes. La obra tiene una construcción narrativa en la que los propios personajes adultos, al regreso de los funerales de Beatriz, narran la historia y representan algunas de sus escenas como un modo de reconstruirla y aprehender su sentido. Puede decirse que el acto narrativo de los personajes constituye la culminación del rito sacrificial con la asunción de su culpabilidad por parte de los tres adultos y su comprensión del irremediable cambio que habrá en sus vidas.

Tanto Jorge Díaz como Egon Wolff destacan en su brillante generación por el volumen y calidad de su dramaturgia y, además, por extender su producción

\footnotetext{
Sobre las características del juego, véase Johan Huizinga, Homo ludens. Buenos Aires-Barcelona: Emecé Editores, 1966. También Roger Caillois, Los juegos y los hombres. La máscara y el vértigo. México: Fondo de Cultura Económica, 1986. Sobre el concepto de "sombra", véase el trabajo de M. L. von Franz "El proceso de individuación": "Cuando en nuestros sueños surgen figuras oscuras y parecen necesitar algo, no podemos estar seguros de si personifican simplemente una parte sombría de nosotros mismos o el "sí-mismo" o ambos a la vez. Adivinar de antemano si nuestro oscuro compañero simboliza una escasez que tenemos que superar o un trozo de vida que tenemos que aceptar; este es uno de los más difíciles problemas que encontramos en el camino de la individuación”. En Carl C. Jung y otros, El hombre y sus símbolos. Madrid: Aguilar, 1974, p. 175.
} 
y vigencia hasta los inicios del nuevo siglo, en permanente búsqueda de nuevas formas expresivas.

\section{DRAMATURGOS DE FIN DE SIGLO}

La dictadura militar que se inició con el golpe de 1973 definió el devenir teatral de las décadas de 1980 y de 1990 en tanto se convirtió en el anclaje que determinó la enunciación dramática. Así, el modo de representar la realidad se tornó una cuestión vital y problemática, en un contexto de represión y de censura, por lo que el mundo solo pudo ser referido oblicuamente. Por ello, si en los años 80 no se podía decir ni mostrar y en los años 90 se buscaba en algunos casos superar una historia nefasta, el lenguaje y los modos de representación se convirtieron en un problema estético y político per se que afectó las búsquedas dramáticas y teatrales de una generación completa, la de Juan Radrigán, Ramón Griffero, Marco Antonio de la Parra, Benjamin Galemiri, Marcelo Sánchez y otros. En esta oportunidad nos referiremos específicamente a Juan Radrigán y a Marco Antonio de la Parra, primero, por las continuidades e innovaciones que presentan con la tradición, y segundo, porque ambos, con propuestas muy diferentes, se han transformado en hitos significativos del teatro chileno. Radrigán, porque se convirtió en una de las voces más representativas del drama nacional generando una escuela y siendo un referente para dramaturgos, directores y actores. De la Parra, porque con las características de su trabajo intertextual abre un camino que recorrerán con similitudes y distancias, autores posteriores.

Tal como la crítica especializada ha insistido, la singularidad de la obra de Radrigán reside en una poética que le da voz y representación a la marginalidad a través de personajes, espacios, oficios, temas y problemas representativos de esta franja social -urbana o campesina- que se define por su orfandad, desprotección y carencia. Esta especificidad, es sin lugar a duda, fruto de su experiencia biográfica y, al mismo tiempo, una herencia de la tradición anterior, principalmente de G. Luco Cruchaga, A. Moock, A. Acevedo Hernández, así como de Isidora Aguirre. Como en sus predecesores, hay una férrea voluntad de representatividad del mundo popular en una cosmovisión que se configura y presenta a través del folclore, los mitos y sobre todo del habla coloquial, urbana, provinciana y campesina. Sin embargo, pese a la aparente representatividad de una realidad nacional absolutamente reconocible, se instala una distancia y desfamiliarización 
del espectador con la ficción radriganiana ${ }^{6}$. Esta dimensión es lo que ya se destaca en "Representación y trascendencia de lo absurdo en el teatro chileno contemporáneo" (1999) de Eduardo Thomas, en el único artículo de la Revista que se detiene en los dramaturgos de los años 80, particularmente en Radrigán y de la Parra. Nos referimos a la 'dimensión trágica' que allí se plantea, que aleja a la dramaturgia de Radrigán del naturalismo y que junto a los elementos de carácter poético y simbólico contribuyen a "desrealizar la representación" (17) ${ }^{7}$. Esta desrealización se configura de dos maneras. La primera de ellas, ya mencionada en el citado artículo, se vincula con la 'universalización' de lo particular. En esta forma, si bien los personajes y el lenguaje, así como las coordenadas espacio temporales son claramente reconocibles en la historia y el territorio chileno, los alcances y repercusiones de los problemas tratados se universalizan, trascendiendo la coyuntura epocal y nacional, apelando a una ética universal a partir de un leitmotiv que cruza su obra: la dignidad de la condición humana. Para algunos críticos esta característica acerca su dramaturgia a ciertas formas del teatro del absurdo que han abordado la condición trágica y absurda de la existencia en la época contemporánea. Sin embargo, este rasgo en común tiene en este caso siempre un anclaje histórico, la dictadura.

El problema de la dignidad humana en su obra adopta al menos dos tratamientos. En su producción de los años 80 -El loco y la triste (1980), Las brutas (1980), Hechos consumados (1981), El toro por las astas (1982), El pueblo de mal amor (1986), Borrachos de luna (1986), entre otras- la dignidad emerge como una ética en medio de la desterritorialización y la desposesión social con una clara intención autorial por rescatar a figuras marginales del olvido y darles una nueva voz en el teatro como ya lo había hecho Acevedo Hernández ${ }^{8}$. Por otra parte, en sus obras de los años 90 y particularmente

6 Utilizamos el galicismo ‘desfamiliarización' por sobre la noción de extrañamiento, tomándolo de la reflexión que realizan Jean Paul Sartre y Albert Camus en "Para un teatro de mitos" (1979), "El estilo dramático" (1979) y "Sur l' avenir de la tragédie" (1962) sobre el lenguaje como recurso dramático por excelencia para lograr distancia y efecto.

Sobre el carácter trágico en la obra de Radrigán, véase también los textos posteriores "La tragedia popular en Juan Radrigán" de María de la Luz Hurtado, y "La seducción del relato en la dramaturgia de Juan Radrigán" de Carola Oyarzún, recogidos en el libro Radrigán. Colección ensayos críticos. Santiago: Eds. Universidad Católica de Chile, 2007.

Recuérdese que la representatividad social de la dramaturgia de los años 50 y 60 , de Egon Wolff y Sergio Vodanovic, se centraba mayoritariamente en la clase media burguesa. 
en las de los 2000, en un contexto de transición y establecimiento de la democracia, el problema adquiere claramente un tratamiento político. Si en las primeras piezas el olvido se mostraba como parte del abandono social, histórico y actual de una sociedad que se encaminaba al 'progreso', las obras del nuevo milenio instalan la memoria como ejercicio y gesto político-estético en una época amnésica frente al olvido de la violencia y represión políticas del pasado. Por ello, si la producción bajo dictadura puede considerarse como una 'tragedia popular' en términos de María de la Luz Hurtado (2007), la verbalización de la memoria en una sociedad que busca superar y olvidar el trauma se convierte en un acto de resistencia y preservación de la dignidad que puede alcanzar ribetes trágicos como sugiere el mismo Radrigán en "Memorias del olvido".

De esta manera, desarraigo, marginación, olvido y memoria aparecen como constantes que son permanentemente reelaboradas por Radrigán en directa relación y diálogo muchas veces sordo - ab-surdus-con el contexto, ya sea por lo que no se puede decir bajo dictadura o por lo que se preferiría callar y olvidar bajo democracia. Es así como según Catherine Boyle, se manifiestan "realidades no habladas y para algunos ni siquiera imaginadas" (55). A nuestro parecer, estas 'realidades no habladas' forman parte de la desrealización de la realidad en su teatro que se construye a través de una segunda vía: el lenguaje. Probablemente una de las grandes innovaciones de Radrigán en la dramaturgia nacional sea la exploración que realiza con el lenguaje y que se funda en una paradoja. De un lado, la incorporación del habla coloquial a través de los múltiples sociolectos, en los que se cuela la imaginación, el humor, la ironía, la farsa, refranes y modismos chilenos, que se nutre de la gran tradición de Acevedo Hernández, Luis Alberto Heiremans e Isidora Aguirre. Esa incorporación de lo 'oído y lo hablado', de una oralidad popular viva -transcrita inclusive fonéticamente en sus textos-hacen de él un 'juntador de palabras' como se describe a sí mismo en su ocupación de testigo de la historia de su nación. La falsa modestia con que describe su artesanía lingüística se confronta con la profunda exploración y variados ejercicios

\footnotetext{
“Al menos para mí, está fuera de cualquier posibilidad de comprensión, de olvido, de perdón. Y aquí es donde el asunto toma visos de tragedia, porque la vida dice que a pesar de los hombres arrojados al mar, que a pesar de los sepultados en cal dentro de los hornos y de los hijos de las violaciones, aún se puede ser feliz. Y yo digo que no, que esa felicidad es una afrenta para los torturados y asesinados, que sin castigo para los culpables, no habrá civilización posible ("Memorias del olvido" 18).
} 
que realiza con las posibilidades que le ofrece el lenguaje dramático y que oscilan desde el diálogo en sticomitia -breve, incisivo, cortante y muchas veces elusivo-, al trabajo con los monólogos y la inclusión de los relatos -formas testimoniales también tributarias en parte de esa oralidad que se resiste a desaparecer en su obra-.

La perturbación y desfamiliarización que se suscita entre la ficción radriganiana y el público, no radica necesariamente en presentar un mundo que está por lo general alejado u oculto para el espectador que consume teatro en Chile -obreros, prostitutas, locos, maestros chasquillas, kiosqueros, dirigentes sindicales, expropiados e indigentes entre otros-; sino en los tipos de discursos de estas voces que se densifican en escena. El director, Rodrigo Pérez, señalaba que a Radrigán "hay que saber leerlo", lo que implica percibir los distintos planos de significación a los que se abre su discurso, más allá de la ‘transcripción' del habla coloquial. Consideramos que cuando Radrigán asumía que su obra "agredía al prójimo" (Memorias del olvido 16), se refería a esta provocación discursiva y a la profunda convicción del lenguaje como límite y posibilidad, como preámbulo y como clausura, como falacia y como esperanza. En este marco, las cercanías y distancias con los así llamados dramaturgos del absurdo -Camus, Beckett y el propio Jorge Díaz-se hacen visibles. Si para Jorge Díaz el teatro era una búsqueda expresiva de comunicación y en eso radicaba, en parte, el carácter mítico del lenguaje como encuentro primordial ${ }^{10}$, para aquellos autores europeos el lenguaje dramático debía convertirse en un límite, una frontera que distancia al espectador y lo lleva a advertir las resonancias e implicancias de las palabras. Así, las incisiones, elusiones y connotaciones de los diálogos - particularmente en las obras de los años 80- se convierten en expresión de esas realidades no habladas, de lo no dicho, de lo silenciado, pero también de la posibilidad. Con ello, la soledad, el abandono, la incomunicación, la orfandad y la solidaridad no aparecen solo como expresión de una marginalidad, sino como el fundamento de la precariedad de la existencia que se exhibe paradigmáticamente en un lenguaje embozado: debajo de la expresión popular y en una aparente ineficacia comunicativa, la asertividad radica en la paradojal indigencia del lenguaje que es al mismo tiempo la posibilidad del encuentro de subjetividades fragmentadas y aisladas.

10 Véase Eduardo Thomas, "Representación y trascendencia de lo absurdo en el teatro chileno contemporáneo" (1999). 
La recuperación de la democracia y la instalación de un nuevo gran relato estructurado en torno a la reconciliación buscaba cohesionar la realidad nacional fracturada por la dictadura. El levantamiento de la censura trajo consigo el reagrupamiento de muchas colectividades y una efervescencia teatral que experimentaba con nuevos lenguajes, fundamentalmente escénicos, y que se caracteriza en gran medida por la creación grupal. En esta sociedad en tránsito, bizca, mirando hacia atrás y adelante, la historia y la identidad aparecían como grietas que requerían ser elaboradas a través de nuevos lenguajes. En este escenario, las autorías de Ramón Griffero ${ }^{11}$ y Marco Antonio de la Parra destacan ya en los años 80 por la búsqueda de nuevas textualidades dramáticas y escénicas, capaces de elaborar lo silenciado, resistiendo el olvido en la reposición constante de la memoria y, en el caso específico de De la Parra, en la alusión permanente a la identidad nacional.

De acuerdo con Adolfo Albornoz (2006), tres son los grandes ejes que cruzan su dramaturgia: el problema del olvido y la memoria, la relación entre la identidad individual y colectiva y el trabajo intertextual. Nos centraremos específicamente en este último porque se vincula estrechamente con el problema del lenguaje y los modos de representación. En el trabajo de la Revista ya citado, "Representación y trascendencia de lo absurdo en el teatro chileno contemporáneo", se analiza la obra La secreta obscenidad de cada día (1984) a partir del juego paródico que realiza el autor con la desmitologización de dos figuras centrales de la cultura occidental moderna, Sigmund Freud y Carlos Marx y "las utopías modernas simbolizadas por ellos, a las que se degrada en acciones exhibicionistas, represivas, terroristas" (27). En el artículo se señala cómo la obra misma se plantea como agresión y escándalo ya en la década de los 80 . Más allá del voyeurismo, exhibicionismo y las abiertas referencias sexuales, el escándalo de la pieza radicaba en el tono lúdico, cínico y desacralizador tanto de las figuras dramáticas como de sus discursos en el juego de roles que asumen. Como señalamos anteriormente, el juego como ejercicio desmitificador, revelador y liberador se instala en el teatro

11 Hacemos una mención especial a Ramón Griffero, quien a lo largo de su trayectoria ha explorado en nuevos lenguajes dramáticos y escénicos, búsquedas contenidas en su libro Dramaturgias del espacio y explicitadas ya desde Cinema Utoppia (2003) hasta La iguana de Alessandra (2018). El trabajo con los mitos, los juegos de roles, el problema de la memoria y la circularidad de la historia han estado presentes a lo largo de su producción y especialmente en sus últimas piezas: Tus deseos en fragmentos (2002), Fin de eclipse (2007), Prometeo (2014), La iguana de Alessandra (2018). 
chileno ya con Egon Wolff, pero se radicaliza ahora en tanto el contexto de los años 90 es completamente diferente. El tono y actitud de este juego se manifiesta provocadoramente y contrasta abierta y de manera displicente con las temáticas y tonos de la década anterior pero también con las propuestas más serias de la época. En este sentido, el juego que dramatiza y escenifica De la Parra, lleva el signo de lo que Linda Hutcheon (2000) definió como parodia para caracterizar el proceder compositivo del arte contemporáneo. Esto es, la yuxtaposición de dos o más textos-discursos reconocibles en una obra que, al entrar en relación se friccionan, relativizando los relatos convocados como provocación directa al macro relato epocal. Consideramos que es esta la actitud y también la acción que el psiquiatra-dramaturgo realiza en sus obras de los años 90: El padre muerto (1991), Tristán e Isolda (1993), Ofelia o la madre muerta (1994), La pequeña historia de Chile (1994), La puta madre (1997), entre otras. A diferencia del trabajo intertextual de autores posteriores, y del mismo Radrigán en los $2000^{12}$, para De la Parra los textos de la tradición -Tristán e Isolda, Hamlet, La Orestíada, entre otros- cobran atractivo en tanto mitos de la cultura occidental con un valor antropológico y simbólico cuyas huellas universales se actualizan -residualmente- en relatos locales (De la Parra y Hurtado 38) ${ }^{13}$. No se trata de argumentos que se recuperan para ficcionalizar una situación cuando no se puede hablar o cuando se busca un modo ficcional para representar la realidad como ocurre en muchas de las reescrituras contemporáneas. El mismo autor se concibe como un "relator de (restos) de mitos", que le permiten representar simbólicamente los temas que le preocupan en el contexto de postdictadura: una sociedad que transita peligrosamente a la amnesia, anestesiada por el exitismo y el consumo, donde la identidad -individual, colectiva y nacional-, los proyectos y sueños

12 Durante las últimas dos décadas, Radrigán trabajó con textos y autores de la tradición, escribiendo nuevas versiones, como es el caso de Medea mapuche (2000), La tempestad (2015) y un diálogo con Ricardo III en El príncipe contrahecho (2016). También con su versión del mito cristiano de la caída en El príncipe desolado (1998) y el diálogo con Samuel Beckett en Beckett y Godot (2000). En todas ellas, el dramaturgo explicita su conocimiento, apropiación y trabajo con los textos de la tradición, incorporando en sus reescrituras en clave seria y no paródica, los grandes motivos de su dramaturgia vinculados a la historia nacional: el exilio, el poder, la memoria, el olvido, entre otros.

13 Es interesante apuntar en virtud de la continuidad de la tradición dramática nacional, que esta actualización simbólica y antropológica de los mitos está ya presente en La viuda de Apablaza de Luco Cruchaga, como señalamos al inicio, aun cuando con un tratamiento y valoración completamente diferentes. 
se desvanecen. Como ya se apunta en La secreta obscenidad de cada día, donde "[t]odo lo sólido se desvanece en el aire", mostrando paródicamente el sino de la modernidad ya señalado por Marshall Berman.

La disyuntiva entre la memoria y el olvido, así como la recuperación de una identidad, es elaborada paradigmáticamente en La pequeña historia de Chile, donde la Historia es concebida como un relato más, un mito, sometido a relectura e interpretación a través de la parodia. Es así como en un liceo pobre con alumnos ausentes, los profesores fantasmales y acuartelados, perseguidos por las deudas, deciden reinventar la historia de Chile. Esto, porque ante la pérdida del puntero, del mapa, la tiza, la pizarra, los alumnos, la bandera y la memoria, no pueden recordar ni la geografía ni el relato que define al país. Deciden entonces construir ficticiamente una nueva cartografía, que no reproduce una historia de fracasos y muertes -la de Caupolicán, de Balmaceda, de O'Higgins, de Prat y Allende- sino el delirante relato de victorias que aglutina, a modo de pastiche, todos los hitos fundacionales de Occidente en Chile: con gladiadores en Atacama, Aristóteles en Perquenco, Cristo en Elqui, Santiago convertido en París, Talca en Londres, Tokio como la zona franca de Iquique, Nietzsche como profesor de alemán en Osorno y una serie de otras ficciones. La yuxtaposición caótica y surrealista de figuras y eventos de la historia universal es transpuesta a un escenario local como alegórica ficción de la derrota y como crítica a una sociedad amnésica, que en el contexto de los años 90 busca blanquearse, parodiando los macrodiscursos políticos en torno a la reconciliación y superación del trauma para construirse de nuevo. En esta línea, De la Parra se hace eco de una generación que ve con escepticismo, desconfianza y desdén los procesos de transición política, como se expresa en uno de los diagnósticos sociológicos más agudos de la época, en el texto Chile, anatomía de un mito (1997) de Tomás Moulian.

Como hemos visto anteriormente, el ejercicio intertextual con relatos literarios, históricos y de la cultura popular no es un procedimiento nuevo en la dramaturgia nacional -recuérdese Gilles de Raiz de Huidobro, Cicatrices de Wolff, Lautaro, epopeya del pueblo mapuche de Aguirre, entre otrospero sí, un camino fructífero para las siguientes generaciones que harán de esta práctica un ejercicio composicional ${ }^{14}$. Lo particular del trabajo de De la

14 En los apartados anteriores hemos destacado el trabajo intertextual que realizan Huidobro y Wolff y nos parece importante mencionar en esta instancia la propuesta de Isidora Aguirre por dos razones. Primero, porque siguiendo nuestra tesis sobre la continuidad en la 
Parra es el gesto paródico en el socavamiento de los referentes canónicos -la literatura y la historia-, y la actitud lúdica y corrosiva que tiene al incrustarlos en su propia obra, en una época en que todavía los textos y los referentes culturales se consideraban símbolos totémicos, como él mismo señalaba. Su desacralización le sirve para denunciar un estado de las cosas de los años 90, poblado de ambigüedad, incerteza y falta de propuestas concretas, que se materializa en la provocación que busca remecer a una sociedad todavía pasmada o de plano alienada ${ }^{15}$.

tradición dramática nacional, Aguirre constituye un referente central para los dramaturgos coetáneos y posteriores. No solo en la incorporación de la dimensión folclórica, oral y popular con una dramaturgia de denuncia política-social, heredera de la tradición brechtiana, sino porque, además, la creación de Lautaro, epopeya del pueblo mapuche se muestra ya en la década de los años 80 como un ejercicio que recuperarán las dramaturgias posteriores. Esto por cuanto su (re)escritura sobre el cacique mapuche y el conquistador español se construye sobre el material histórico de las cartas de Valdivia al rey Carlos y a partir de su experiencia y contacto directo con el pueblo mapuche. Por ello, como señala Eduardo Thomas en el artículo "Metáforas de la identidad en el teatro hispanoamericano contemporáneo", "los datos históricos y antropológicos se subordinan a la experiencia directa y vital de la dramaturga con la realidad mapuche" (47), estableciendo un cruce similar a la praxis que desarrollará Manuela Infante con Prat y Juana, que referimos más adelante.

La segunda razón para esta mención especial es la ausencia de artículos críticos sobre la dramaturga en el marco de los estudios sobre teatro chileno en la Revista. Las únicas dos referencias a ella están en el artículo recién citado sobre teatro hispanoamericano (1997) y en la reseña del libro Teatro y fulgor. Aproximaciones a la obra de Isidora Aguirre (2018).

15 Es esta línea la que también explorará Benjamín Galemiri en sus propios trabajos intertextuales Edipo asesor (2000) e Infamante Electra (2005). A propósito de El coordinador (1993), el autor ya señalaba sobre su poética: "Si yo pudiera definir mi teatro, yo diría que hago obras satíricas, desde una perspectiva moral, a través de un lenguaje poético. [...] pienso que nuestra vida diaria está cargada de absurdo, de ironía, de ternura, de búsqueda desesperada de comprensión y que en la depuración de nuestro lenguaje está la redención. Por eso digo que mi teatro describe el desconcierto que sufre una persona o un grupo de personas ante el descubrimiento de una moral". B. Galemiri, "La trampa del viaje gratis o el teatro como un viaje", p. 27.

El trabajo intertextual y el tono provocador, son propios de las de reescrituras de Benito Escobar en Ulises o no (2006) y de Rolando Jara en El complejo de Edipo (2009). 


\section{DRAMATURGIAS DEL NUEVO MILENIO}

El derrotero iniciado por Marco Antonio de la Parra adquiere un desarrollo muy atractivo y características propias en las dramaturgias del nuevo milenio. Esto, por cuanto el trabajo intertextual se convierte en uno de los ejes compositivos más recurrentes, pero con un acento y una propuesta diferentes al tono mordaz, satírico y cínico que se observa en las obras anteriormente mencionadas. Dentro del heterogéneo grupo que se inicia en la escritura y estrena sus obras desde el 2000, encontramos propuestas tan diversas como las de Alexis Moreno, Cristián Soto, Ana Harcha, Juan Claudio Burgos, Nona Fernández, Luis Barrales, Guillermo Calderón y Manuela Infante, entre otros ${ }^{16}$. Pese a las diferencias de sus poéticas teatrales, existen algunas variantes recurrentes: su relación con la historia (nacional), la forma de aprehender y elaborar la realidad y la clara insistencia por desmarcarse del realismo en una dramaturgia que interroga sus propias formas de composición y escenificación, a través de distintas estrategias, particularmente en el uso de los 'materiales'. Estas características responden a su vez a una serie de factores necesarios de tener a la vista. El primero y más evidente es el hecho de haber nacido y crecido en dictadura, condición que determina una distancia frente al trauma directo que permite hablar y elaborar de una manera distinta la historia. Segundo, este grupo es partícipe de un mundo globalizado y conectado, que integra la comunicación y la tecnología, así como diversos referentes que provienen de múltiples ámbitos -la literatura, el teatro, la televisión, la cultura, la publicidad, los mass media, entre otros- sin jerarquizarlos. A lo anterior, $\mathrm{y}$, en tercer lugar, se suma su formación literaria y teatral y el conocimiento de la tradición dramática nacional y universal que enriquece su concepción del texto y de la escena, incidiendo en su enunciación y representación. Esto último determina en gran medida, su carácter rupturista e innovador en las formas de representación del presente y del pasado y en la utilización de 'materiales' para componer una realidad ficcional.

16 La diversidad de creadores que comienzan a difundir sus obras se debe en parte al nuevo escenario teatral que incluye más espacios formales para la representación, nuevas escuelas de teatro, plataformas institucionales que patrocinan la actividad dramática, como la Muestra Nacional de Dramaturgia, nuevas editoriales independientes que publican las obras, así como las plataformas digitales. Al grupo mencionado de dramaturgos se suman: Benito Escobar, Ana López Montaner, Lucía de la Maza, Cristián Figueroa, Cristián Soto. 
El único artículo de la Revista que se detiene a observar este fértil panorama teatral de los 2000 es el estudio "Intertextos y memoria en Juana de Manuela Infante" (2010) de Eduardo Thomas, que analiza la obra de la dramaturga y directora. Pese a la ausencia de otros trabajos críticos, la detención en Infante es paradigmática por cuanto permite auscultar el proceso compositivo de muchos de sus coetáneos. Así, en dicho artículo se postula que "la poética teatral de Infante considera el arte como instrumento de reflexión crítica sobre los relatos sustentados por los discursos sociales, en especial de la historia", a través de un modo "de elaborar las figuras históricas para someterlas a un proceso de resemantización" (82). Lo anterior se verifica en dos obras paradigmáticas, Prat y Juana, las que son analizadas a partir de los diferentes intertextos que entran en relación y fricción, con el objetivo de lograr un distanciamiento crítico de los espectadores y con ello una actitud que relativiza los discursos sociales, particularmente los históricos, como relatos verdaderos y hegemónicos. En el caso de Juana, Infante construye su heroína haciendo converger tres intertextos: el tratamiento desmitificado del personaje histórico de Orléans que realiza Bernard Shaw en Santa Juana, la concepción de Rodolfo Usigli del teatro como espacio para "pensar y revitalizar el imaginario de la cultura nacional" (Thomas, "Intertextos" 189) y finalmente la recepción que hizo Vicente Huidobro del personaje histórico Gilles de Rais en su versión de Gilles de Raiz, adoptando la idea de la invención del mito como construcción imaginaria e histórica. De acuerdo con el artículo, la interacción y fusión de estos tres intertextos en Infante muestra la comprensión del teatro como instrumento de reflexión sobre las estructuras de poder de los imaginarios sociales, al tiempo que se muestra a sí mismo como "liturgia renovadora" de dichas concepciones (Thomas, "Intertextos"189).

Tradicionalmente, el trabajo intertextual ha posibilitado retomar argumentos y personajes para 'hacerlos hablar' en un contexto diferente. Esa transposición y, en muchos casos, transplantación y travestismo, ha buscado la desmitificación y desacralización de modelos, ideologías y de un imaginario cultural. Infante y sus coetáneos -a diferencia del trabajo que realiza De la Parra- se hacen parte de esa tradición, pero suman una comprensión diferente de los textos y de la creación misma. Es interesante advertir cómo esta generación de creadoras y creadores se hace eco de una tendencia mundial que concibe los textos (de la tradición y de los contemporáneos), así como los discursos epocales, como materiales para una composición. Para gran parte de la dramaturgia contemporánea, 'material' designa tanto a los textos que concurren en la composición como al texto mismo que resulta del ensamblaje de todos 
ellos y que se dispone para una representación ${ }^{17}$. Los textos, personajes y argumentos, literarios e históricos, se convierten en elementos disponibles para la creación y, en el caso de estas dramaturgias, la historia nacional se vuelve uno de los materiales dilectos para la composición. La reescritura de la historia nacional, parodiada ya en La pequeña historia de Chile, constituye ahora un modo serio de representación de la realidad que busca separarse del realismo tradicional, persiguiendo la desfamiliarización y la reflexión crítica.

Consideramos que las formas de representación en las dramaturgias del Bicentenario responden a lo que J. P. Sarrazac denomina "dramaturgias del rodeo", formas dramáticas que operan sobre la distancia como núcleo de aproximación, paradojalmente "dándole la espalda a la realidad que sin embargo parecen enfocar" (22). Esto, en la medida en que no se retrata el objeto, sino que se da cuenta de él oblicuamente, presentándose como un realismo del cuestionamiento, "un realismo no en busca de realidad sino de verdad" (22). Las estrategias para estas formas de un realismo indirecto son múltiples y se diseminan en las diversas propuestas de estas dramaturgias, donde podemos reconocer algunas técnicas recurrentes, de tipo argumental y estéticas. Dentro de las primeras encontramos la utilización de figuras históricas canonizadas que, paradojalmente, son despojadas de sus atributos heroicos o legendarios y presentadas en sus vicisitudes y tribulaciones ${ }^{18}$ así como figuras tomadas del imaginario cultural de la prensa y televisión, hitos y eventos nacionales -históricos y contingentes-, presentados desde la dimensión individual o colectiva, pero de forma íntima y no monumental ${ }^{19}$.

17 Para la noción de material en la dramaturgia contemporánea, véase Florence Baillet y Catherine Naugrette, "Material" en J. P. Sarrazac (dir.) Léxico del drama moderno y contemporáneo.

18 A las mencionadas Juana y Prat se suman Cristo (2008) de Manuela Infante, Manuel Rodríguez en Yo, Manuel (2010) de Cristian Ruiz, Pedro de Valdivia: la gesta inconclusa (2009) de Francisco Sánchez, O'Higgins, un hombre en pedazos (2016) de Cristián Kalawski y Ricardo Larraín, Xuárez (2016) de Luis Barrales y M. Infante.

19 Por ejemplo, la figura y caso de Hans Pozo y "las arañitas", delincuentes juveniles famosos en la prensa y recogidos por Luis Barrales en HP (2007) y Niñas araña (2008), respectivamente; la figura de Lady Di (princesa de Gales) en Los tristísimos veranos de Lady Diana (2017) de Carla Zúñiga, las movilizaciones estudiantiles que dieron origen a Clase (2008) de Guillermo Calderón, La mala clase (2009) de Luis Barrales; Al volcán (2010) de Gerardo Oettinger inspirada en la tragedia de Antuco del año 2005; Hilda Peña (2014) de Isidora Stevenson inspirada en el atentado del faro de Apoquindo en 1993; Mateluna (2016) de G. Calderón inspirada en la condena de Jorge Mateluna por el asalto a un banco en el 2013; Entre-crónicas de Cristián Ruiz que toma como sustrato el caso bombas Pitronello; entre otras. 
A su vez, el pasado de la dictadura es recuperado y reposicionado como tema de discusión, explorando de manera distanciada en sus consecuencias y repercusiones en la sociedad civil, en la medida en que se trata de generaciones que no experimentaron directamente el trauma, pero que sí se han moldeado a la luz de las transformaciones y heridas que dicho periodo instaló ${ }^{20}$.

Las estrategias estéticas que contribuyen a la desfamiliarización provienen en buena medida de la tradición dramática anterior, pero son intensificadas en virtud del efecto. Así, la estructura fragmentaria de la trama que se dispone a través del montaje de escenas persiguiendo que el espectador reconstruya una linealidad es un recurso ampliamente utilizado y ya introducido desde los postulados de Brecht por Isidora Aguirre y retomado por Infante, Barrales y otros. De igual forma, los finales abiertos que buscan que el destinatario complete la significación. En la no resolución, los dramaturgos evitan explicitar una posición autorial exclusiva y excluyente, exigiendo al espectador concluir una interpretación y juicio propios.

Es en el plano del lenguaje donde podemos advertir, tal vez de forma más palmaria la recuperación de la tradición dramática nacional, así como una exploración más radical. Por una parte, el lenguaje coloquial, el 'habla viva' de la calle traspuesta a la ficción -aquella que exigían Acevedo Hernández, Aguirre y Radrigán-, es un elemento que funciona en un doble nivel: de un lado 'acerca' al espectador -reconociendo el referente extradramático- al tiempo que lo fustiga, distanciándolo. La desfamiliarización desde el lenguaje en estas dramaturgias se logra a su vez de diversos modos: utilizando la ironía, explorando en las posibilidades del monólogo y exhibiendo una fuerte autorreferencialidad.

Como ya describimos anteriormente, la ironía como fuente de distanciamiento y ejercicio crítico tuvo un gran exponente en Jorge Díaz. Fernando Burgos señala que el procedimiento irónico en dicha dramaturgia funciona como "sobrecargamiento" dirigiendo la atención sobre el lenguaje como producción y como acto (133-141). Con ello se logra la distorsión y manipulación de los contextos, el montaje de los diversos registros comunicativos, la representación de juegos dramáticos y la celeridad del diálogo, entre varios otros efectos. Muchas de estas posibilidades son exploradas en la dramaturgia de Guillermo

$20 \quad$ Ejemplo de estas temáticas son Villa de G. Calderón, Liceo de niñas de Nona Fernández, No tenemos que sacrificarnos por los que vendrán de Juan Pablo Troncoso, entre otras. 
Calderón, quien hace de este tropo semántico el soporte estructural de sus diálogos dramáticos y de la construcción de sentido ${ }^{21}$.

La exploración con el monólogo como textualidad discursiva es un vínculo claro con las búsquedas estéticas de Radrigán. En sus obras, el monólogo se instala como lugar de enunciación último de sus figuras marginales. En este acto de habla íntimo se exhiben identidades violentadas y expropiadas, y por lo mismo, el habla monológica pareciera ser la última y desesperada vía de afirmación de la individualidad, y el lenguaje, la última propiedad de las víctimas, como se muestra en Diatriba de la empecinada (2004). En este marco, es significativa la constatación que realizan Hausbi y Heulot en torno al estatuto del monólogo en el teatro contemporáneo, indicando que se convierte "en el espacio abierto de una palabra en busca de interlocutor" 22 . Su carácter convulsivo, fragmentario, que tropieza con el silencio, es expresión de identidades estalladas que buscan reconocerse en la enunciación dramática. Esta operación es la que observamos con matices y diferentes grados en HOMBREconpieSOBREunaespaldadeNIÑO de Juan Claudio Burgos, Rey Planta de Manuela Infante e Hilda Peña de Isidora Stevenson, entre otras.

Probablemente el rasgo que diferencia a esta generación del Bicentenario de la tradición anterior sea la fuerte autorreferencialidad que exhibe, que se vincula directamente con su comprensión de la ficción y con este 'realismo del rodeo'. El uso de la ironía, la reflexividad del lenguaje, la explicitación de los materiales en los diversos intertextos que desmontan y vuelven a ensamblar, los juegos de roles y/o representacionales, son estrategias que buscan una desfamiliarización para forzar un posicionamiento crítico del destinatario, así como procedimientos expresos para mostrar el carácter ficcional y representacional de las obras. Nutriéndose de lo real -la historia, la realidad cotidiana, la realidad virtual de la tecnología- y de distintos discursos - literarios, políticos, históricos, publicitarios y tecnológicos- estas dramaturgias desmontan esos elementos constitutivos, precisamente para componerlos y darles una realidad y lectura a través de sus escrituras. No se trata de una mímesis que busca capturar la realidad en todos sus detalles, sino más bien, parafraseando a Sarrazac, "ofrecernos un punto de mira sobre

21 Véase, por ejemplo, Diciembre, Clase, Beben, y en dramaturgos posteriores como Pablo Manzi en Donde viven los bárbaros.

${ }_{22}$ K. Hausbi y F. Heulot. "Monólogo", en J. P. Sarrazac (dir.). Léxico del drama moderno y contemporáneo. 
el mundo, a partir del cual la ficción teatral pueda apuntar, alcanzar, penetrar el núcleo de lo real" (66).

\section{CONCLUSIONES}

El recorrido histórico trazado en estas páginas no ha pretendido ser una sucinta historia del teatro en Chile; objetivo inatendible por diversas razones. En primer lugar, porque hemos dejado mayoritariamente fuera los aspectos vinculados a la representación y recepción de los montajes, así como las condiciones de escenificación teatral en cada una de las épocas revisitadas. Segundo, porque generalmente las 'historias' están construidas por el lente y voz de un crítico que define un determinado marco teórico y enfoque de aproximación a temas que selecciona y jerarquiza.

Por el contrario, desde nuestro lugar de enunciación y análisis, la Revista Chilena de Literatura, en el contexto de su centena de números publicados, elegimos realizar un panorama crítico de los hitos del drama chileno en y desde la Revista. Así, el panorama implicó detenerse en una serie de dramaturgos y dramaturgas $-\mathrm{y}$ en algunas obras particulares- sancionados ya como canónicos a partir de una muestra representativa de estudios sobre ellos. De esta manera, nuestra revisión acoge una diversidad de miradas críticas, con sus respectivos enfoques teóricos, sobre diversos problemas estéticos en la dramaturgia chilena que, en su lectura transversal, son posibles de aunar en torno a nuestra propuesta: la construcción de un canon y tradición dramática nacionales.

Este canon dramático está conformado por textos que no solo han sobrevivido más allá de la representación en una edición impresa, sino de manera importante, a través de la crítica de la que han sido objeto.

En esta línea, consideramos que, pese al número limitado de artículos sobre dramaturgia chilena, los diecinueve trabajos en la Revista-consignados todos ellos en el apéndice final- han contribuido con su rigurosidad intelectual a la consolidación de una tradición dramática, al destacar en sus análisis los temas y problemas recurrentes, así como las innovaciones dramáticas y estéticas de los diversos dramaturgos y dramaturgas. Reiteración e invención se convierten así en los dos movimientos -simultáneos y secuenciales- que caracterizan la oscilación de pleamar y reflujo de la tradición dramática chilena. Dada la extensión de este trabajo, agrupamos estos movimientos en dos líneas 
argumentales descritas inicialmente: la representación de la realidad y el trabajo intertextual. La primera de ellas, en la medida en que el desarrollo dramático del siglo XX chileno -así como latinoamericano y europeo- se caracteriza por el interés de incorporación y representatividad de lo real, indagando en formas más o menos cercanas al realismo decimonónico. Hemos visto a través de los distintos autores examinados cómo la integración de la tradición nacional y popular en su folclore, lenguaje, historia, costumbres y leyendas convive con manifestaciones que se 'despegan' de lo real y concreto, acercándose a expresiones simbolistas y vanguardistas, así como aquellas dramaturgias que exhiben sus mundos ficcionales al tiempo que explicitan su condición de construcciones dramáticas. Paralelamente nos hemos detenido en el trabajo intertextual, precisamente porque hemos abordado las obras como textos que entran en relación con otros textos y discursos, principalmente los literarios y los históricos y que por ende construyen esta cadena histórica que llamamos tradición. Desde ambos lineamientos, la representación de la realidad y la intertextualidad, hemos accedido al mundo ficicional construido por los dramaturgos y dramaturgas, deteniéndonos en la construcción de mundos, personajes, lenguaje, estructura, entre otros, todas ellas categorías del análisis dramático.

El sintético panorama crítico del drama chileno que hemos expuesto a partir de las contribuciones a la Revista Chilena de Literatura se alinea con la misión institucional, social y cultural de la Universidad de Chile que ya en 1941 dio vida al Teatro Experimental de la Universidad de Chile y a su revista Teatro, creaciones que constituyen una inflexión decisiva en el desarrollo dramático y teatral nacional. Esto, en la medida en que parte de sus objetivos era resguardar y contribuir a la memoria y tradición nacional con dedicados montajes de obras nacionales, así como fortalecer el ambiente teatral a través de la rigurosidad, especialización y profesionalización de las distintas áreas y la difusión de su programa estético y social desde las giras nacionales y la revista Teatro. Disuelta la colectividad del Teatro Experimental tras el golpe de 1973 y con ello el giro innovador y riguroso en el quehacer teatral, la reflexión teórica y crítica sobre la dramaturgia chilena desde la Universidad de Chile se concentra mayoritariamente en la Revista Chilena de Literatura, desde su primer número en 1970 hasta el 2018. Parte de esas reflexiones han sido recogidas en este trabajo y, a nuestro juicio, contribuyen a fortalecer la memoria y la tradición en el drama chileno. 


\section{BIBLIOGRAFÍA}

Albornoz, Adolfo. "Marco Antonio de la Parra, tres décadas de teatro chileno 1973-2006 (Un comentario general a propósito de Chile y su clase media en los tránsitos dictadura/ postdictadura, modernidad/postmodernidad)". Acta Literaria 33 (2006): 109-132.

Baillet, F. y C. Naugrette. "Material". Léxico del drama moderno y contemporáneo. J. P. Sarrazac (dir.). México: Paso de Gato, 2013. 121- 127.

Barría, Mauricio. "Interrupciones momentáneas de la convención. Aportes para la comprensión de Irredentos de Antonio Acevedo Hernández". Revista Chilena de Literatura 90 (2015): 29-54.

Boyle, Catherine. "Lecturas lejanas, lecturas cercanas: entrar en la selva lingüística de Juan Radrigán”. Radrigán. Colección Ensayos críticos. Ed. Carola Oyarzún. Santiago: Eds. Universidad Católica de Chile, 2008. 47-76.

Burgos, Fernando. "Estética de la ironía en la obra de Jorge Díaz". Revista Chilena de Literatura 27-28 (1986): 133-141.

Camus, Albert. "Sur l'avenir e la tragedie". Conférence prononcée à Athènes. Théâtre, récits, nouvelles d'Albert Camus. Paris: Gallimard, 1962.

Caillois, Roger. Los juegos y los hombres. La máscara y el vértigo. México: Fondo de Cultura Económica, 1986.

Carrasco, Iván. "Flores de papel de Egon Wolff: la crisis de la identidad". Revista Chilena de Literatura 20 (1982): 114-132.

Castedo-Ellerman, Elena. El teatro chileno de mediados del siglo XX. Santiago: Editorial Andrés Bello, 1982.

De la Parra, Marco Antonio y María de la Luz Hurtado. "El nuevo teatro chileno". La escena latinoamericana 3 (1989).

Galemiri, Benjamín. "La trampa del viaje gratis o el teatro como un viaje”. Revista Apuntes 108 (1995): 25-27.

Goic, Cedomil. Los mitos degradados. Ensayos de comprensión de la literatura hispanoamericana. Amsterdam: Rodopi Editions, 1992.

Hausbi, K. y F. Heulot "Monólogo". Léxico del drama moderno y contemporáneo. J. P. Sarrazac (dir.). México: Paso de Gato, 2013. 137-141.

Huizinga, Johan. Homo ludens. Buenos Aires-Barcelona: Emecé Editores, 1966.

Hurtado, María de la Luz. "La tragedia popular en Juan Radrigán”. Radrigán. Colección Ensayos críticos. Ed. Carola Oyarzún. Santiago: Eds. Universidad Católica de Chile, 2008. 13- 46.

Hutcheon, Linda. A Theory of Parody: The Teaching of Twentieth-Century Art Forms. Illinois: University of Illinois Press, 2000.

Innes, Christopher. El teatro sagrado y la vanguardia. México: F.C.E, 1992.

Neghme Echeverría, Lidia. "El creacionismo político de Huidobro en En la Luna". Latin American Theatre Review 18 (1984): 75-82.

Oyarzún, Carola. "La seducción del relato en la dramaturgia de Juan Radrigán". Radrigán. Colección Ensayos críticos. Ed. Carola Oyarzún. Santiago: Eds. Universidad Católica de Chile, 2008. 77- 100. 
Parra, Clara María (Reseña). "María Martínez, Jessica Améstica, Nora Fuentealba y Vjera Milosevic. Teatro y fulgor. Aproximaciones a la obra de Isidora Aguirre. Valparaíso: Euv/ Ediciones Dársena, 2016”. Revista Chilena de Literatura 98 (2018): 405-409.

Pereira, Sergio. "El drama legendario y bíblico de Antonio Acevedo Hernández". Revista Chilena de Literatura 54 (1999): 71-88.

Pérez, Rodrigo. "Estupefacto, disconforme y proclive a la angustia, Juan Radrigán”. Crónicas del amor furioso. Juan Radrigán. Santiago: Eds. Frontera Sur, 2004.

Radrigán, Juan. "Memorias del olvido". Crónicas del amor furioso. Santiago: Eds. Frontera Sur, 2004.

Saldes Báez, Sergio: "El juego de los espejos. Función ideológica y función poética en En la luna de Huidobro". Revista Chilena de Literatura 29 (1987): 98-117.

Sarrazac, Jean Pierre. Juegos de sueño y otros rodeos. Alternativas a la fábula en la dramaturgia. México: Ed. Paso de Gato, 2011.

Sartre, Jean Paul. Un teatro de situaciones. Buenos Aires: Ed. Losada, 1979.

Skármeta, Antonio. "El motivo de la oposición entre aldea y ciudad en dos dramas chilenos". Revista Chilena de Literatura 1 (1970): 31-41.

"La burguesía invadida: I. Egon Wolff". Revista Chilena de Literatura 4 (1971): 91-102.

Thomas, Eduardo. "Metáforas de la identidad en el teatro hispanoamericano contemporáneo". Revista Chilena de Literatura 50 (1997): 39-50.

"Representación y trascendencia de lo absurdo en el teatro chileno contemporáneo". Revista Chilena de Literatura 54 (1999): 5-30.

"El juego y el rito como fundamentos de la estructura dramática en tres dramas de Egon Wolff: Cicatrices, Flores de papel, Invasores". Revista Chilena de Literatura 66 (2005): 5-27.

"Intertextos y memoria en Juana de Manuela Infante". Revista Chilena de Literatura 77 (2010): 181-192.

Von Franz, M.L. "Sobre el proceso de individuación". Carl Jung y otros: El hombre y sus símbolos. Madrid: Aguilar, 1974.

\section{APÉNDICE}

ÍNDICE COMPLETO DE COLABORACIONES SOBRE TEATRO CHILENO

EN LA REVISTA ChILENA DE LiteratuRA POR ORDEN DE PUBLICACIÓN

Skármeta, Antonio. "El motivo de oposición entre aldea y ciudad en dos dramas chilenos". Revista Chilena de Literatura 1 (1970): 31-41. 91-102.

"La burguesía invadida: I. Egon Wolff". Revista Chilena de Literatura 4 (1971): 
Thomas, Eduardo. "Moscas sobre el mármol de Luis Alberto Heiremans: el fantasma en la caballeriza". Revista Chilena de Literatura 9-10 (1977): 41- 58.

Carrasco Muñoz, Iván. "Flores de papel de Egon Wolff: la crisis de la identidad". Revista Chilena de Literatura 20 (1980): 114-132.

Burgos, Fernando. "Estética de la ironía en el teatro de Jorge Díaz". Revista Chilena de Literatura 27-28 (1986): 133-141.

Saldes Báez, Sergio. "El juego de los espejos. Función ideológica y función poética en En la luna de Huidobro". Revista Chilena de Literatura 29 (1987): 88- 117.

Thomas, Eduardo. "Flores de papel de Egon Wolff: la sombra de la burguesía". Revista Chilena de Literatura 30 (1987): 55-73.

"Ficción y creación en cuatro dramas chilenos contemporáneos". Revista Chilena de Literatura 33 (1989): 61- 70.

Gotschlich, Guillermo (Reseña). "Eduardo Thomas Dublé. La poética teatral de Luis Alberto Heiremans". Revista Chilena de Literatura 44 (1994): 158-160.

Neghme, Lidia (Nota). "Chiloé cielos cubiertos (1972) y algunas técnicas del teatro popular". Revista Chilena de Literatura 46 (1995): 91-96.

De Castro, Percio B. (Nota). “La muerte y la doncella: ¿De quién son las bolas? Opresor oprimido y viceversa”. Revista Chilena de Literatura 52 (1998): 61-67.

Pereira, Sergio. "El drama legendario y bíblico de Antonio Acevedo Hernández". Revista Chilena de Literatura 54 (1999): 71-80.

Thomas, Eduardo. "Representación y trascendencia de lo absurdo en el teatro chileno contemporáneo". Revista Chilena de Literatura 54 (1999): 5-30.

"El juego y el rito como fundamento de la estructura dramática en tres obras de Egon Wolff: Los invasores, Flores de papel y Cicatrices". Revista Chilena de Literatura 66 (2005): 5-27.

Zaliasnik, Yael. “¿Re/posición? De Tres Marías y una Rosa: tres décadas para a-bordar la resistencia". Revista Chilena de Literatura 77 (2010): 193- 215.

Thomas, Eduardo. "Intertextos y memoria en Juana de Manuela Infante". Revista Chilena de Literatura 77 (2010): 181-192.

Barría, Mauricio. "Interrupciones momentáneas de la convención: aportes para la comprensión de Irredentos de Antonio Acevedo Hernández". Revista Chilena de Literatura 90 (2015): 29-54.

Sandoval, Osvaldo. "Hacia una retórica de la presencia en el exilio en la dramaturgia de Jorge Díaz y Jerónimo López Mozo”. Revista Chilena de Literatura 97 (2018): 297-316.

Parra, Clara María (Reseña). "María Martínez, Jessica Améstica, Nora Fuentealba y Vjera Milosevic. Teatro y fulgor. Aproximaciones a la obra de Isidora Aguirre. Valparaíso: Euv/ Ediciones Dársena, 2016”. Revista Chilena de Literatura 98 (2018): 405-409. 